\title{
Sensory and chemical attributes of dessert wines made by different freezing methods of Marselan grapes
}

\author{
Viktoriia Ostapenko ${ }^{1}$, Oksana Tkachenko ${ }^{1}$, Eldar Iukuridze ${ }^{2}$ \\ 1 - Odesa National Academy of Food Technologies, Odesa, Ukraine \\ 2 - Industrial-trading company Shabo, LTD, Odesa region, Shabo, Ukraine
}

\section{Keywords:}

Icewine

Marselan

Freezing

Northen Black Sea

coast.

\section{Article history:}

Received 02.02.2017

Received in revised form 19.05.2017

Accepted 29.06.2017

\section{Corresponding \\ author:}

Viktoriia Ostapenko

E-mail:

ostapenkoviktoriya7@

gmail.com

ORCID: 0000-0002-

$8965-4224$

DOI: $10.24263 / 2304-$

974X-2017-6-2-9

\section{Abstract}

Introduction. The purpose of research was to determine the impact of different freezing methods of Marselan grapes on sensory and physicochemical compositions of obtained icewines.

Materials and methods. Sweet wines were obtained by two ways of freezing of Marselan grapes: naturally and alternative cryogenic extraction. The production and physicochemical parameters of wines were conducted in agreement with the provisions of the International Organization of Vine and Wine relating to icewine technology. Quantitative and qualitative composition of aromatics in sweet wines were determined by gas chromatography. Sensory analysis consistent with ISO 8586-2 showed the organoleptic attributes of dessert wines.

Results and Discussion. According to the agricultural climatic resources of Northen Black Sea coast exactly in Odesa region red variety Marselan is suiTable for processing into dessert wine of premium sector. Freezing of grapes by cryogenic extraction was slower and at a lower temperature $\left(-10^{\circ} \mathrm{C}\right)$ compare to natural method (harvesting at $-7^{\circ} \mathrm{C}$ ) for obtaining of must with a high sugar content.

The chemical composition of the wine grape Marselan, frozen in various ways were not significantly different. Positive correlations among the variables responsible for the content of sugar, ethanol and volumetric mass concentrations of volatile acids were observed in both samples. 35 and 37 aroma compounds were found in wines made by natural (NF) and alternative freezing (AF) respectively by gas chromatography. Concentrations of alcohols in both wines were the highest among aroma volatiles counting more than $60 \%$ and $40 \%$ in wines of $\mathrm{NF}$ and AF accordingly. Esters, higher alcohols, volatile acids differ in mass concentration, and $\mathrm{C}_{6}$ compounds were found only in the wine produced from grapes frozen on the vine. Sensory analysis showed differences in intensity of fruit notes, hints of nuts and longitude of aftertaste.

Conclusions. The results of the research demonstrate the peculiarities in the formulation of unique aromatic and chemical profiles of icewines made from Marselan, as well as a way of freezing affects the defining characteristics of the wines. 


\section{Introduction}

Using the new varieties in non-classic technologies impacts on developing of original wines whereby expanding of range inside market. Icewine is relatively new wine type for production of which particular conditions are required [1]. An agricultural climatic factors and cold resistant cultivars are the main aspects to obtain frozen grapes from vines. The white skinned varieties are widely applicable in atypical technology but recently winemakers have started to freeze dark grapes that also can withstand frosts [2].

To our knowledge icewine from Marselan grapes had not been produced in the world and its aromatic and chemical characteristics also had not been investigated in scientific literature [1], [2], [7], [8]. Marselan cultivar originated from cross-breeding of Cabernet Savingnoun and Grenache in France [3] was chosen due to characteristics appreciated for icewine grapes including thick skin, late maturing variety with a high natural acidity. A cold resistant of variety was determined through leaving grapes on vines after major of harvest had been picked for another wine types from vineyards of Shabo. Riesling is considered as king of icewine grapes in the world [4] but unfortunately due to the distribution of precipitation most of which was high in months of autumn cultivar was rotten in Northen Black Sea coast, Odesa region, Ukraine (Figure 1).

In order to avoid lost entire amount of grapes intended for icewine before temperatures will be cold producers use artificial methods of freezing. Place is especially important in wine grape production because soils and climate cannot be modified by humans, and thus geographic branding has become increasingly spatially specific [5].

The aim of current article was to determine the peculiarities of aromatic and chemical compositions of wines obtained by natural and alternative freezing of Marselan grapes. The main objectives of research were to compare chemical and sensory properties of dessert wines. The expected practical result was to produce the new premium wine possessing unique aroma and flavor due to atypical technology.

\section{Materials and methods}

Grape materials. In December of 2016 Marselan grapes from vineyards belonged to terroir of Shabo in Northen Black Sea coast, Odesa region, Ukraine were harvested and pressed at required level of temperature according to Definition of the vitivinicultural products by code sheet of OIV [6]: $-7^{\circ} \mathrm{C}$. The sugar content of obtained must was over 300 $\mathrm{mg} / \mathrm{l}$ that is accordance with international documentation about icewine production. Two month earlier another portion of Marselan grapes had been frozen using refrigerator during one week until statutory sugar level was reached in berries (until $-10^{\circ} \mathrm{C}$ ). The grapes had been picked while technological ripeness of variety was observed on October of 2016.

Fermentation. The intense advertence is devoted to choice of yeast strain that contributes to chemical and sensory attributes thereby question of optimal and suiTable yeast for icewine is still discussed by major of producers and researchers [7], [8], [9], [10], [11]. Before fermentation musts were clarified by Microcol bentonite alpha (Laffort CO., France) with concentration of $1 \mathrm{~g} / 1$ combined with Polylact (Laffort CO., France) for effective fining. The adding of Assotan (Esseco SRL, Italy) contributed to essential antioxidant protect. Both samples of must formerly heated to $18-20{ }^{\circ} \mathrm{C}$ were inoculated with Saccharomyces cerevisiae VIN 2000 hybrid (Anchor, South Africa) at rate of $5 \mathrm{~g} / \mathrm{dal}$. The yeast starter was prepared by such wise: 1) rehydration of yeast to intended concentration $5 \mathrm{~g} / \mathrm{dal}, 2$ ) after 15 minutes of rehydration equal volume of yeast and must previously heated to $28-30^{\circ} \mathrm{C}$ were mixed and then resulted started was left during 1 hour, 
3 ) in this starter equal volume of sweet must was added and left at temperature of $25-30{ }^{\circ} \mathrm{C}$ stirring every 45 minutes. The yeast starter was appended triply: in $1^{\text {st }}$ day of fermentation, after 2 days of fermentation and after one week in order to acclimatization and accumulation of yeast biomass. Also to reducing the fermentation time and increasing the rate of process simultaneously complete fermentation activator and yeast nutrient Maxaferm (DSM Food Specialties B.V, The Netherlands) with concentration of $2 \mathrm{~g} / \mathrm{dal}$ and Booster Blanc (Lallemand, Canada) with concentration of $3 \mathrm{~g} / \mathrm{dal}$ were added to both musts after 2 days of beginning of fermentation. The aforementioned nutrients were diluted in water 1:10 and supplemented one time.

Chemical methods. Chemical analysis was conducted according to prevailing laws in winemaking of Ukraine and international documentation regard to icewine production. The sugar content of must was measured by Digital Hand-Held "Pocket" Refractometer PAL1 (Atago CO., LTD, Japan) and then converted from Brix into g/l using Table giving the sugar content of musts and concentrated musts in grammes per liter recommended by OIV [12]. The $\mathrm{pH}$ was determined by $\mathrm{pH}-$ meter S220 (Mettler-Toledo International Inc., Switzerland). The concentration of titrated acid (TA) was determined in accordance with first method of GOST 14252-73. Concentrations of volatile acids (VA) were identified by analytical equipment Apparatus for the extraction of volatile acidity by direct distillation 116300 (Dujardin-Salleron Laboratory, France).

Determination of volatiles in the wines was carried out using of Gas chromatography Agilent Technology 7890A (Agilent Technologies, Inc., USA). The main characteristics of chromatograph utilized in ascertainment of volatiles are following Silica capillary column VF-WAXms $60 \mathrm{~m}$, the carrier gas was helium at rate of $3 \mathrm{ml} / \mathrm{min}$, column diameter $-0,33$ $\mathrm{mm}$, the temperature of the evaporator and the detector pointed $245^{\circ} \mathrm{C}$, the temperature of thermostat was from 450 to $245^{\circ} \mathrm{C}$ with rate of $40 / \mathrm{min}$, sample volume $-1 \mathrm{mcl}$. The concentration was calculated according to the method of absolute calibration. A pentanolstandard solution (internal standard $-5 \mathrm{mg} / \mathrm{l}$ and $1 \mathrm{ml}$ of methylene chloride) were added to $10 \mathrm{ml}$ of wine base. After stirring for 2 hours on a magnetic stirrer methylene chloride layer was separated, which had been evaporated by pure nitrogen gas flow to a volume of 50 microliters. The extract was analyzed by a chromatograph mass spectrometry detector. The components were identified by comparing the mass spectra of the substances identified in the chromatogram and of the standard library of mass spectra. The concentration was calculated according to the ratio of the peak areas pentanol $(5 \mathrm{mg} / \mathrm{l})$ and the identified peaks of volatile substances without correction factors.

All methods of determination of wine and must compositions were conducted in producing laboratory of winery «Shabo» in triplicate. Data about amount of precipitation was obtained from meteocenter of territory where Shabo is located.

Sensory assessment. Analysis of organoleptic attributes of dessert wines were done in laboratory of sensory analysis of Odesa national academy of food technologies (ONAFT), Odesa, Ukraine by a panel of 10 judges who had trained according to ISO 8586-2 [13]. The most applicable descriptive terms had been selected during tasting to create own aromatic profile of dessert wines.

Statistical analysis. In order to determine differences in sensory and chemical attributes of obtained wines XLSTAT (Addinsoft; Paris, France) statistical software was performed. The diversity between chemical variables of grape musts and wines Factor analysis was utilized (Table 1, Table 2). LSD test showed the influence of temperatures on sugar contents of Marselan grapes frozen by refrigerator $(\mathrm{p} \leq 0,05)$ (Table 3). ANOVA (Assessor/Descriptors) was carried to calculate which descriptors had had the biggest influence on sensory parameters using grade scale with anchors at 0 to 7 . Anchors for 
parameters of length of aftertaste and color were labeled as low intensive and high intensive, for other attributes grades were characterized as low or high starting from 0 . Using Descriptive analysis mean scores of descriptors defined by each judges were determined (Figure 2). Means and its standard deviations of volatiles of 2 dessert wines were calculated (Table 4). All Figure s were created using Excel software (Microsoft Office, USA).

\section{Results and discussion}

\section{Natural and alternative freezing of Marselan grapes}

Marselan originated from south of France and favored in hot climate withstood frequent precipitation especially during October in Northern Black Sea coast, Odesa region that also is important to produce rare wine without loses of grapes caused by high water status in ground before first frosts (Figure 1).

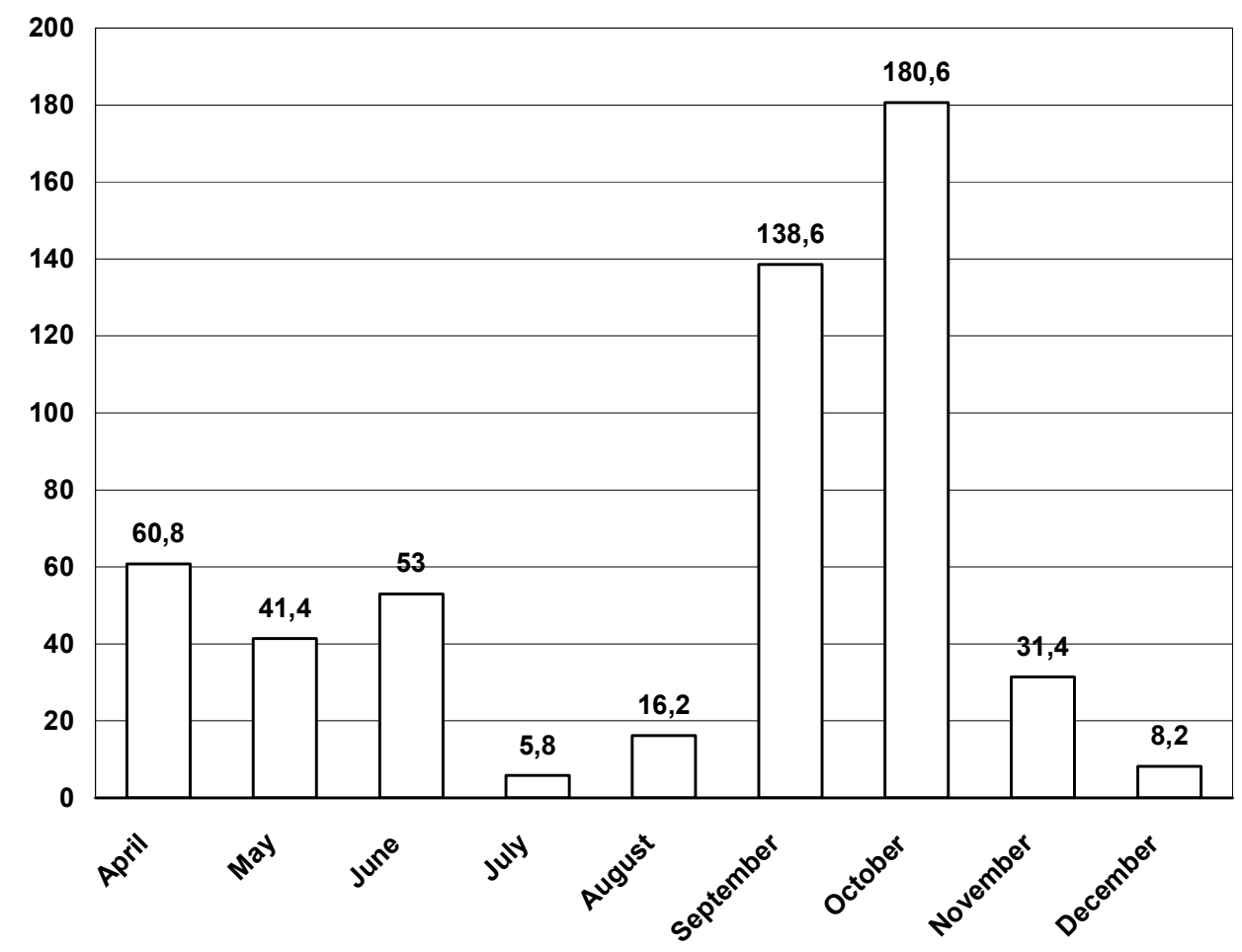

Figure 1. Precipitation from April to December of 2016 in Shabo, mm

The value of water for technological characteristics of grapes is essential: the more precipitation in the period of active vegetation of the plant, especially the berries growth, the higher the acid content in the grapes and aromatic substances [14]. 
In sequential decrease in temperature $\left(-6^{\circ} \mathrm{C},-8^{\circ} \mathrm{C},-10{ }^{\circ} \mathrm{C}\right)$ for Marselan grapes harvested at the technological maturity in wine season 2016 have been frozen using the refrigerator working around the clock for seven days. The influence of different level of temperatures on sugar content of cultivar is represented in Table 3. Due to the the structure of thick peel variety achieved proper level of sugar needed for the production of dessert wines such as Icewine only under the lowest temperature $-10^{\circ} \mathrm{C}$ in refrigerator compared to natural freezing, when temperature was $-7^{\circ} \mathrm{C}$.

Table 1

Pearson correlation matrix for Marselan musts made by natural and alternative freezing

\begin{tabular}{|c|c|c|c|}
\hline Variables & Sugar content & TA & pH \\
\hline Sugar content & $\mathbf{1}$ & $\mathbf{0 , 9 8 4}$ & $-0,987$ \\
\hline TA & $\mathbf{0 , 9 8 4}$ & $\mathbf{1}$ & $-0,957$ \\
\hline pH & $-0,987$ & $-0,957$ & $\mathbf{1}$ \\
\hline
\end{tabular}

Data based on 6 samples. Values in bold are different from

0 with a significance level alpha $=0,05$

Pearson correlation matrix for wines produced by 2 different treatments

Table 2

\begin{tabular}{|c|c|c|c|c|c|}
\hline Variables & Sugar content & TA & pH & Ethanol & VA \\
\hline Sugar content & $\mathbf{1}$ & $\mathbf{0 , 7 8 4}$ & 0,000 & 0,983 & $\mathbf{0 , 8 6 9}$ \\
\hline TA & $\mathbf{0 , 7 8 4}$ & $\mathbf{1}$ & $-0,032$ & $\mathbf{0 , 7 2 0}$ & $\mathbf{0 , 8 9 9}$ \\
\hline pH & 0,000 & $-0,032$ & $\mathbf{1}$ & $-0,101$ & $-0,348$ \\
\hline Ethanol & $\mathbf{0 , 9 8 3}$ & $\mathbf{0 , 7 2 0}$ & $-0,101$ & $\mathbf{1}$ & $\mathbf{0 , 8 6 1}$ \\
\hline VA & $\mathbf{0 , 8 6 9}$ & $\mathbf{0 , 8 9 9}$ & $-0,348$ & $\mathbf{0 , 8 6 1}$ & $\mathbf{1}$ \\
\hline
\end{tabular}

Data based on 6 samples. Values in bold are different from 0 with a significance level alpha $=0,05$

Regardless of freezing treatment both wine sample had the same correlations between variables - parameters (Table 2). Volatile acidity had positive association with sugar content due to activity of hyperosmotic stress of yeasts that had contributed to increasing of acetic acid. Also the higher sugariness the biggest concentration of ethanol was produced likely for reason of fermentation conversion into alcohol. The positive correlation between titraTable acidity and sugar content can be explained by freezing that concenters all substances of grapes passing into wine (Table 1, Table 2). Level of $\mathrm{pH}$ was independent from sugar content and negatively correlated with other attributes.

\begin{tabular}{|c|c|c|c|}
\hline Temperature, ${ }^{\circ} \mathrm{C}$ & $\begin{array}{c}(1) \\
318,23\end{array}$ & $\begin{array}{c}(2) \\
306,90\end{array}$ & $\begin{array}{c}(3) \\
287,33\end{array}$ \\
\hline-10 & & 0,018164 & 0,000121 \\
\hline-8 & 0,018164 & & 0,001436 \\
\hline-6 & 0,000121 & 0,001436 & \\
\hline
\end{tabular}

Table 3 
The data of LSD test showed significant differences between the samples of grapes emphasizing the effect of temperature on the sugar content of berries (Table 3). The largest difference of sugar content was observed in grapes at $-6^{\circ} \mathrm{C}$ sequential triple freezing, which is associated with activation of biochemical processes, due to a sharp decrease of temperature.

\section{Sensory evaluation}

According to descriptive analysis (Figure 2) wine produced by natural freezing is characterized by fruits notes including perceived nuances of pear, plum and apricots. The character of tropical fruits such as figs, banana of dessert wine made by alternative method was higher compared to first sample. The citrus aromas were more notable in wine grapes for which had been frozen in refrigerator but nutty tones were higher in experimental icewine. The lowest taste of spicy and caramel and approximately the same honey tins were presented in both wines. Length of aftertaste of wine obtained from naturally frozen Marselan was more intensive and deeply colored, than another sample.

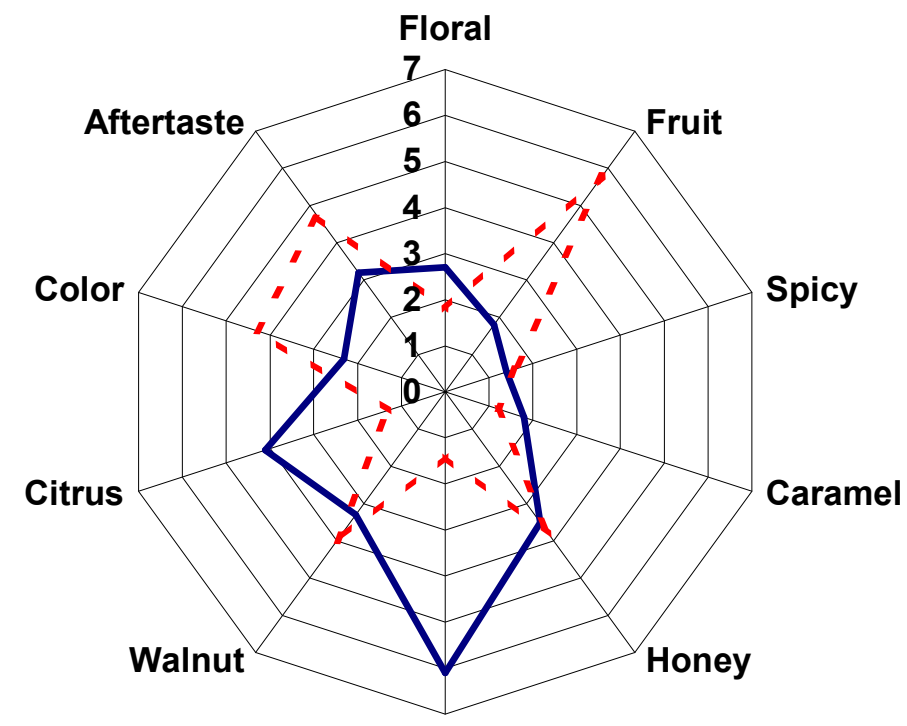

Tropical fruits

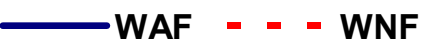

Figure 2. Biplot of sensory descriptors of dessert wines

Results of ANOVA shown that scores determined by each judges were different and distinguished significantly $(\mathrm{F}=18,883, \mathrm{p}=0,051)$. The abovementioned descriptors were chosen by consensus. Each assessor proposed aroma characteristics according to own perception. Thus, terminology was ascertained for conducting of tasting. In general, the scores of all descriptors were not differed significantly estimated by judges. The most variation was presented in evaluation of intensity of caramel, walnut and citrus. The whole compliance was reached in determining of aromas of fruits, spicy and color. 


\section{Volatile compositions}

In wine made by natural freezing (NF) 35 compounds were detected and 37 ones were found in wine of alternative freezing (AF). Means of volatiles and its standard deviations are represented in Table 4 . Chemical standards, quantitative and qualitative ions for icewine and dessert wine from Marselan variety are shown in Table 5.

Means and standard deviations of volatiles of 2 dessert wines

Table 4

\begin{tabular}{|c|l|l|l|}
\hline № & \multicolumn{1}{|c|}{ Volatiles } & \multicolumn{1}{|c|}{ Wine of NF } & \multicolumn{1}{|c|}{ Wine of AF } \\
\hline 1 & Phenylethyl Alcohol & $74,85 \pm 0,502$ & $55,13 \pm 0,0125$ \\
\hline 2 & 3-methyl- 1-Butanol & $63,93 \pm 0,562$ & $53,60 \pm 0,687$ \\
\hline 3 & 2-methyl-1-Propanol (isobutanol) & $9,51 \pm 0,044$ & $7,52 \pm 0,045$ \\
\hline 4 & 1-Propanol & $8,37 \pm 0,468$ & $6,10 \pm 0,358$ \\
\hline 5 & 2,3-Butanediol & $5,17 \pm 0,003$ & $11,17 \pm 0,001$ \\
\hline 6 & 3-ethoxy-1-Propanol & $1,64 \pm 0,302$ & $0,46 \pm 0,301$ \\
\hline 7 & 1-Butanol & $0,63 \pm 0,044$ & $0,65 \pm 0,047$ \\
\hline 8 & 3-methyl-1-Pentanol & $0,22 \pm 0,019$ & $0,23 \pm 0,017$ \\
\hline 9 & 3-(methylthio)-1-Propanol & $0,21 \pm 0,050$ & $0,23 \pm 0,058$ \\
\hline 10 & 1-Octen-3-ol & $0,11 \pm 0,004$ & \\
\hline 11 & 1-Hexanol & $0,78 \pm 0,273$ & $0,63 \pm 0,217$ \\
\hline 12 & Cis-3-Hexen-1-ol & $0,06 \pm 0,001$ & \\
\hline 13 & 3-methyl-1-Butanol, (Isoamile acetato) & $31,50 \pm 2,109$ & $32,72 \pm 0,128$ \\
\hline 14 & Ethyl Hexanoate & $8,31 \pm 1,639$ & $9,25 \pm 1,247$ \\
\hline 15 & Ethyl butyrate & $4,33 \pm 0,804$ & $3,87 \pm 0,812$ \\
\hline 16 & Ethyl hydrogen succinate (monoethyl ester) & $3,02 \pm 1,670$ & $2,06 \pm 1,238$ \\
\hline 17 & Ethyl octanoate & $4,44 \pm 0,358$ & $8,26 \pm 1,647$ \\
\hline 18 & 2-Phenethyl acetate & $2,28 \pm 0,424$ & $6,04 \pm 0,547$ \\
\hline 19 & Diethyl succinate & $1,70 \pm 0,071$ & $0,71 \pm 0,078$ \\
\hline 20 & Ethyl decanoate & $1,35 \pm 0,164$ & $3,45 \pm 0,161$ \\
\hline 21 & Ethyl lactate & $0,95 \pm 0,090$ & $0,89 \pm 0,07$ \\
\hline 22 & Ethyl 3-hydroxybutyrate & $0,27 \pm 0,038$ & $0,25 \pm 0,09$ \\
\hline 23 & 3-Ethoxypropyl acetate & $0,23 \pm 0,036$ & $0,10 \pm 0,031$ \\
\hline 24 & Hexyl acetate & $0,19 \pm 0,005$ & $0,35 \pm 0,001$ \\
\hline 25 & 1,3-propanedioldiacetate & $0,19 \pm 0,004$ & $0,19 \pm 0,005$ \\
\hline 26 & Benzaldehyde & $0,58 \pm 0,014$ & \\
\hline 27 & Benzeneacetaldehyde & $0,43 \pm 0,007$ & $0,24 \pm 0,007$ \\
\hline 28 & Acetoin & $0,15 \pm 0,023$ & $1,93 \pm 0,067$ \\
\hline 29 & N-(3-Methylbutyl) acetamide & $0,11 \pm 0,002$ & \\
\hline 30 & Octanoic acid & $17,44 \pm 0,131$ & $37,51 \pm 0,147$ \\
\hline 31 & Neodecanoic acid & $8,18 \pm 0,076$ & $12,14 \pm 0,029$ \\
\hline 32 & Hexanoic acid & $6,69 \pm 0,432$ & $10,94 \pm 0,427$ \\
\hline 33 & Acetic acid & $5,22 \pm 0,124$ & $7,15 \pm 0,143$ \\
\hline 34 & n-Decanoic acid & $4,80 \pm 0,127$ & $18,88 \pm 0,125$ \\
\hline 35 & Butanoic acid & $0,32 \pm 0,007$ & $0,31 \pm 0,09$ \\
\hline 36 & 3-methyl valeric acid & & $0,57 \pm 0,001$ \\
\hline 37 & 2-Methoxy-4-vinylphenol & $0,18 \pm 0,001$ \\
\hline 38 & Linalol & & $0,53 \pm 0,125$ \\
\hline 39 & Dihydro-2-methyl-3(2H)-Thiophenone & & $0,55 \pm 0,05$ \\
\hline 40 & Ethyl 5-Oxotetrahydrofuran-2-carboxylate & & $0,14 \pm 0,078$ \\
\hline 41 & Ethyl 4-hydroxy-3-methoxybenzoate & & $0,35 \pm 0,097$ \\
\hline & & & \\
\hline
\end{tabular}


Table 5

Chemical standards, quantitative and qualitative ions for Marselan icewine and dessert wine

\begin{tabular}{|c|c|c|c|c|}
\hline $\begin{array}{c}\text { Cas } \\
\text { number }\end{array}$ & Compounds & $\begin{array}{c}\text { Quanti- } \\
\text { fication } \\
\text { ions }(\mathrm{m} / \mathbf{z})\end{array}$ & $\begin{array}{l}\text { Qualitative } \\
\text { ions }(\mathbf{m} / \mathbf{z})\end{array}$ & $\begin{array}{l}\text { Odor } \\
\text { characteristics }\end{array}$ \\
\hline $60-12-8$ & Phenylethyl Alcohol & 91 & 65,51 & Burnt, rose, oily \\
\hline $3391-86-4$ & 1-Octen-3-ol & 57 & 72,82 & Mushroom \\
\hline $928-96-1$ & 3-Hexen-1-ol & 67 & 41,82 & Green grass, resin \\
\hline $123-51-3$ & $\begin{array}{l}\text { 3-methyl- 1-Butanol } \\
\text { (izoamyl alcohol) }\end{array}$ & 55 & 70,42 & $\begin{array}{l}\text { Malt, rancid, } \\
\text { pungent }\end{array}$ \\
\hline $78-83-1$ & 2-methyl-1-Propanol & 43 & 41,31 & Fruity, floral \\
\hline $71-23-8$ & 1-Propanol & 31 & 59,42 & Sweet, ripe fruit \\
\hline $513-85-9$ & 2,3-Butanediol & 45 & 57,89 & $\begin{array}{l}\text { Fruity, buttery, } \\
\text { bitter[36] }\end{array}$ \\
\hline $111-35-3$ & 3-ethoxy-1-Propanol & 31 & 59,45 & Not found \\
\hline $111-27-3$ & 1-Hexanol & 56 & 43,55 & $\begin{array}{c}\text { Leaf, grassy, resin, } \\
\text { medicinal }\end{array}$ \\
\hline $71-36-3$ & 1-Butanol & 56 & 31,41 & $\begin{array}{l}\text { Medicinal, } \\
\text { phenolic }\end{array}$ \\
\hline $589-35-5$ & 3-methyl-1-Pentanol & 56 & 69,41 & $\begin{array}{c}\text { vinous, } \\
\text { herbaceous, cacao }\end{array}$ \\
\hline $505-10-2$ & $\begin{array}{c}\text { 3-(methylthio)-1-Propanol } \\
\text { (Methionol) }\end{array}$ & 106 & 41,53 & $\begin{array}{c}\text { VegeTable, } \\
\text { boiled potato, and } \\
\text { soup-like[36] }\end{array}$ \\
\hline $565-67-3$ & 2-methyl-3-Pentanol & 59 & 59,74 & Fuel \\
\hline $626-89-1$ & 4-methyl-1-Pentanol & 56 & 69,41 & $\begin{array}{c}\text { Almond, toasted, } \\
\text { nutty }\end{array}$ \\
\hline $98-55-5$ & alpha-Terpineol & 59 & 75,63 & $\begin{array}{l}\text { Lilac, Citrus, } \\
\text { Lime, sweet }\end{array}$ \\
\hline $100-51-6$ & Benzyl alcohol & 79 & 85,93 & Floral, fruity \\
\hline $123-92-2$ & $\begin{array}{l}\text { 3-methyl-1-Butanol, } \\
\text { (Isoamile acetato) }\end{array}$ & 43 & 55,70 & Banana \\
\hline $123-66-0$ & Ethyl Hexanoate & 88 & 99,43 & $\begin{array}{l}\text { Fruity, green, } \\
\text { apple, banana }\end{array}$ \\
\hline $105-54-4$ & Ethyl butyrate & 71 & 43,88 & Apple \\
\hline $1070-34-4$ & $\begin{array}{c}\text { Ethyl hydrogen succinate } \\
\text { (monoethyl ester) }\end{array}$ & 101 & 85,94 & Herbaceous \\
\hline $106-32-1$ & Ethyl octanoate & 88 & 101,127 & $\begin{array}{c}\text { Fruity, banana, } \\
\text { pineapple, peach, } \\
\text { sweet }\end{array}$ \\
\hline $103-45-7$ & 2-Phenethyl acetate & 104 & 42,47 & ripe fruit, floral \\
\hline $110-38-3$ & Ethyl decanoate & 88 & & Sweet, grass \\
\hline
\end{tabular}


Table 5 (continue)

Chemical standards, quantitative and qualitative ions for Marselan icewine and dessert wine

\begin{tabular}{|c|c|c|c|c|}
\hline $\begin{array}{c}\text { Cas } \\
\text { number }\end{array}$ & Compounds & $\begin{array}{c}\text { Quanti- } \\
\text { fication } \\
\text { ions }(\mathrm{m} / \mathrm{z})\end{array}$ & $\begin{array}{l}\text { Qualitative } \\
\text { ions }(\mathrm{m} / \mathrm{z})\end{array}$ & $\begin{array}{l}\text { Odor } \\
\text { characteristics }\end{array}$ \\
\hline $97-64-3$ & Ethyl lactate & 45 & 29,75 & Acid, medicine \\
\hline $5405-41-4$ & Ethyl 3-hydroxybutyrate & 43 & 36,49 & Apple \\
\hline $94825-54-4$ & 3-Ethoxypropyl acetate & 43 & 85,63 & Sweet \\
\hline $142-62-1$ & Hexyl acetate & 43 & 56,61 & Fruity, apple, pear \\
\hline $628-66-0$ & 1,3-propanedioldiacetate & 43 & 44,87 & Potato \\
\hline $1126-51-8$ & $\begin{array}{c}\text { Ethyl 5-Oxotetrahydrofuran- } \\
\text { 2-carboxylate }\end{array}$ & 85 & 51,39 & Not found \\
\hline $617-05-0$ & $\begin{array}{l}\text { Ethyl 4-hydroxy-3- } \\
\text { methoxybenzoate }\end{array}$ & 151 & 114,79 & Not found \\
\hline $100-52-7$ & Benzaldehyde & 106 & 111,56 & bitter almond \\
\hline $122-78-1$ & Benzene acetaldehyde & 91 & 58,74 & Almond \\
\hline $513-86-0$ & Acetoin & 45 & 75,98 & Butter flavor \\
\hline $13434-12-3$ & N-(3-Methylbutyl) acetamide & 30 & 44,68 & Vinegar \\
\hline $124-07-2$ & Octanoic acid & 60 & 78,81 & Grass, rancid \\
\hline $26896-20-8$ & Neodecanoic acid & 87 & 56,39 & Strong odor \\
\hline $142-62-1$ & Hexanoic acid & 60 & 45,68 & Cheese \\
\hline $64-19-7$ & Acetic acid & 43 & 69,81 & $\begin{array}{l}\text { Strong odor, } \\
\text { Vinegar }\end{array}$ \\
\hline $334-48-5$ & n-Decanoic acid & 73 & 78,63 & fatty, unpleasant \\
\hline $107-92-6$ & Butanoic acid & 60 & 71,54 & Cheese, rancid \\
\hline $105-43-1$ & 3-methyl valeric acid & 60 & 55,46 & Unpleasant, sour \\
\hline 7786-61-0 & 2-Methoxy-4-vinylphenol & 150 & 54,97 & Spicy clove \\
\hline $78-70-6$ & Linalol & 71 & 101,46 & Flowery \\
\hline $13679-85-1$ & $\begin{array}{c}\text { Dihydro-2-methyl-3(2H)- } \\
\text { Thiophenone }\end{array}$ & 60 & 112,84 & Balsamic \\
\hline
\end{tabular}

Concentrations of alcohols in both wines were the highest among aroma volatiles counting more than $60 \%$ and $40 \%$ in wines of NF and AF respectively. Concentration of Phenylethyl Alcohol in dessert wine obtained by NF of Marselan was higher than in another wine. Such tendency can explain that current alcohol rises with the degree of ripeness of grapes. According to information[15] Phenylethyl Alcohol has the high concentrations in dessert special wines that is agree with current findings and it is more abundant in white wines from Riesling, Chardonnay, Pinot blanc and Gewürztraminer [16].

Alcohol with mushroom odor 1-Octen-3-ol was found only in late-harvest wine which is in agreement with several studies [17], [18], [19]reporting occurrence of alcohol in wines made from overripe grapes and possible rotten by fungal infections. Aforementioned statements coincide with that Marselan grapes used for freezing in refrigerator were clean and health. 
$\mathrm{C}_{6}$ compounds are partly responsible for the green and herbaceous aroma of grapes and wines [20]. High water status in ground, especially during the later stages of ripening have negative effects on wine aroma. Too much water contributes to more vegetal in wine, bell pepper and grassy character [21]. The rainfall during experiment period from late October until December was high, above $200 \mathrm{~mm}$ in total, thus affecting the herbaceous character in Marselan wine made by natural freezing. It should be pointed out that the later harvest date (hanging time of berries on vine) also impacted on the highest concentrations in wines of 1hexanol and Cis-3-Hexen-1-ol [22] [23]. Also the addition of antioxidation agents to the must affects the content of these compounds [24].

Isoamyl alcohol, 1-propanol and Isobutanol had highest concentrations in wine obtained by natural way due to spontaneous alcoholic fermentation of grape must conducted by action of different yeast genera and species [25] that probably were on Marselan grapes before harvest. Also the important factor of forming of higher alcohols as well as N-(3-Methylbutyl) acetamide is adding yeast nutrients including amino acids and ammonium used for must fermentation for both samples. Although, acetomide was not observed in wine produced from frozen grapes synthetically. The effect of the ammonium addition can be explained by the increased capacity of the yeast to transform the synthesized a-ketoacids, avoiding their accumulation and later expulsion to the medium after their reduction to higher alcohols [26], [27], [28]. Concentrations of 3-ethoxy-1Propanol in natural sweet wine was denominated much. This fact accounts for actions of yeast during fermentation. Concentrations of 1-Butanol and 3-methyl-1-Pentanol had been noted distinction in both wine samples. The higher alcohols significantly influence on aromatic of wines possessing pungent and fusel odor, but the most significant aspect of them is their function in the formation of esters [29]. Such substances as 2-methyl-3Pentanol, 4-methyl-1-Pentanol and alpha-Terpineol were identified only in icewine made by alternative method. An alpha-Terpineol is derived from linalool itself and therefore implying its sensorial character [30].

The ethyl 5-Oxotetrahydrofuran-2-carboxylate and ethyl 4-hydroxy-3methoxybenzoate were detected only in wine produced by alternative way and concentrations of majority of other esters were higher compared to esters presented in natural-made icewine. With reference to data [19] decrease of acids in late-harvest grapes effect to forming of esters. As expected concentration of 3-methyl-1-Butanol, (Isoamile acetato) was the highest among all esters in wines that plays important role in aroma background in wines [31]. Ethyl hexanoate, ethyl lactate and ethyl butyrate are responsible for the full-bodied fruity and floral aroma of wine [32]. Tendency to a limited increase of isoamyl and 2-phenethyl acetate was found in dessert wine obtained naturally and previously had been observed in botrytized wines due to the esterase activity of B. cinerea, which probably persisted in the juice [33].

The fatty acids, formed enzymatically during fermentation, constitute an important group of aroma compounds that can contribute with fruity, cheese, fatty, and rancid notes to the wine's sensory properties [34]. Volatile acids such as hexanoic, octanoic and decanoic acids existed in our study were also found in sweet wines from Muskat and Malvasia grapes [35].

In wines made by NF and AF phenylethyl alcohol, 3-methyl- 1-Butanol, 3-methyl-1Butanol, (Isoamile acetato) and octanoic acid had the highest concentrations among others volatiles. Also in wine produced by alternative method concentrations of n-decanoic acid, ethyl hexanoate, acetic acid, acetoin, hexyl acetate, 2-phenethyl acetate, ethyl decanoate, ethyl octanoate and 2,3-butanediol were found in biggest amount compared to natural-made icewine. The standard deviations of volatile substances of 2 dessert wines were not 
significantly high with the exception of ethyl hexanoate and ethyl hydrogen succinate (monoethyl ester) in both samples. The standard deviation of 3-methyl-1-Butanol (Isoamile acetato) of classic icewine was identified as highest among alcohols.

\section{Conclusions}

Firstly, in Ukraine icewine was produced from dark-skinned variety Marselan according to agricultural climatic conditions of Northern Black Sea coast in Odesa region. The physicochemical and aromatic profiles were determined for comparative evaluation of dessert wines obtained by different methods of freezing:

1. Chemical attributes: both wine sample had the same correlations between variables parameters including sugar content, titraTable acidity (TA), volatile acidity (VA), ethanol but $\mathrm{pH}$ was not associated with abovementioned properties.

2. Sensory analysis: nuances of pear, plum and apricots and longest of aftertaste were inherent for natural-made icewine from Marselan and in wine by AF tropical fruits such as figs, banana and citrus perception were identified.

3. Chromatographic analysis: both wine samples were similar to majority of volatile compounds but differ by its concentrations where alcohols and esters were determined as the main aroma indicators characterized by fruity and flowery odors.

Agricultural climatic conditions of Northern Black Sea coast allow to harvest Marselan grapes in winter without alternative freezing, which is energy-consuming in the production of elite wines.

\section{Acknowledgements}

The authors thank to company «Shabo» for grapes and conducting of investigations that consisted of all parts of current article.

\section{References}

1. Pickering G. (2006), Icewine- the frozen truth, Conference paper, pp. 1-29.

2. Ostapenko V. (2016), Analysis on application of different grape varieties in the production of icewine. A review, Ukraininan food journal, 5(4), pp. 678-694.

3. Montaigne E., Alfredo C. Leila K. (2016), Economic issues and perspectives on innovation in new resistant grapevine varieties in France, Wine Economics and Policy, 5, pp. 73-77.

4. Ostapenko V., Tkachenko O., Iukuridze E. (2016), Analysis of market current state and historical roots of ice wine production, Technology audit and production reserves, 5(31), pp. 46-53.

5. Caffarra A. et al. (2012), Modelling the impact of climate change on the interaction between grapevine and its pests and pathogens: European grapevine moth and powdery mildew, Agriculture, Ecosystems and Environment, 148, pp. 89-101.

6. (2015), 4. Special wines. 4.7. Icewine - Eiswein (OENO 6/03)

7. Synos K., Reynolds A.G., Bowen, A.J. (2015), Effect of yeast strain on aroma compounds in Cabernet franc icewines, LWT - Food Science and Technology, 64(1), pp. 227-235. 
8. Martin S.J. (2008), PhD Thesis, The Osmoadaptive Response of the Wine Yeast Saccharomyces cerevisiae KI-Vll16 during Icewine Fermentation, Brock University, St. Catharines.

9. Erasmus D.J., Cliff M., Van Vuuren H.J.J. (2004), Impact of yeast strain on the production of acetic acid, glycerol, and the sensory attributes of icewine. American Journal of Enology and Viticulture, 55(4), pp. 371-378.

10. Pigeau G.M., Inglis D.L. (2005), Upregulation of ALD3 and GPD1 in Saccharomyces cerevisiae during Icewine fermentation, Journal of Applied Microbiology, 99(1), pp. $112-125$.

11. Husnik J. (2003), Autochthonous microbial population in a Niagara Peninsula icewine must Autochthonous microbial population in a Niagara Peninsula icewine must, Food Research International, 36, pp. 747-751.

12. (2016), Compendium of international methods of wine and must analysis, $O I V$, ed.2016, 1, pp. 504.

13. International Standard ISO 8586-2:2008. (2008), Sensory analysis - General guidance for the selection, training and monitoring of assessors - Part 2: Expert sensory assessors, pp. 1-14.

14. Tkachenko O.B., Trinkal' O.V., Pashkovskij O.I. (2015), Vlijanie agrometeorologicheskih uslovij vegetacionnogo perioda na tehnologicheskie svojstva vinograda, Tehnologicheskij audit i rezervy proizvodstva, 3(23), pp. 18-21.

15. Nykänen L., Suomalainen H. (1983), Aroma of Beer, Wine and Distilled Alcoholic Beverages, Springer; 1983 edition (May 31, 1983).

16. Vilanova M. et al. (2013), Determination of Odorants in Varietal Wines from International Grape Cultivars (Vitis vinífera) Grown in NW Spain, 34(2), pp. 212-222.

17. Genovese A. et al. (2007), Sensory properties and aroma compounds of sweet Fiano wine, Food Chemistry, 103(December), pp. 1228-1236.

18. Guerche S. et al. (2006), Characterization of Some Mushroom and Earthy Off-Odors Microbially Induced by the Development of Rot on Grapes, Journal of Agricultural and Food Chemistry, 54, pp. 9193-9200.

19.Bowen A.J., Reynolds A.G. (2015), Aroma compounds in Ontario Vidal and Riesling icewines. I. Effects of harvest date, Food Research International, 76, pp. 540-549.

20. Gomez E., Martinez A. (1995), Changes in Volatile Compounds during Maturation of some Grape Varieties, Journal of the Science of Food and Agriculture, 67, pp. 229233.

21. Qian M.C., Fang Y., Shellie K. (2009), Volatile Composition of Merlot Wine from Different Vine Water Status. Journal of Agricultural and Food Chemistry, 57, pp. 7459-7463.

22. Bowen, A.J., Reynolds A.G. (2012), Odor potency of aroma compounds in Riesling and Vidal blanc Table wines and icewines by gas chromatography-olfactometry-mass spectrometry, Journal of Agricultural and Food Chemistry, 60(11), pp. 2874-2883.

23. Palomo E.S. et al. (2007), Aroma profile of wines from Albillo and Muscat grape varieties at different stages of ripening, Food Control, 18, pp. 398-403.

24. Marchio M. (1996), 3-hexen-1-ol isomers in Muller-Thurgau wines: A "varietal', characteristic affected, Vitis, 35(3), pp. 147-148.

25. Romano P. et al. (2003), Function of yeast species and strains in wine flavour, International Journal of Food Microbiology, 86, pp. 169-180.

26. Yoshizawa K. (2017), On Various Factors Affecting Formation of Isobutanol and Isoamyl Alcohol during Alcoholic Fermentation, Agricultural and Biological Chemistry, 1369(January), pp. 634-641. 
27. Hern P. et al. (2005), Food Chemistry Effect of the addition of ammonium and amino acids to musts of Airen variety on aromatic composition and sensory properties of the obtained wine. Food Chemistry, 89, pp. 163-174.

28. Cacho J. (2002), Relationship between Varietal Amino Acid Profile of Grapes and Wine Aromatic Composition. Experiments with Model Solutions and Chemometric Study, Journal of Agricultural and Food Chemistry, 50, pp. 2891-2899.

29. Moss R. (2015), How higher alcohols and volatile phenols impact on key aromas. WineLand. Available at: http://www.wineland.co.za/how-higher-alcohols-and-volatilephenols-impact-on-key-aromas/.

30. Agrario I., Micheie S. (1994), Aroma components of Galician Albariö, Loureira and Godello wines, Vitis, 170, pp. 165-170.

31. Antalick G. et al. (2015), Influence of Grape Composition on Red Wine Ester Profile: Comparison between Cabernet Sauvignon and Shiraz Cultivars from Australian Warm Climate, Journal of Agricultural and Food Chemistry,pp. 1-9. DOI: 10.1021/acs.jafc.5b00966

32. Tao Y., Li H. (2009), Active volatiles of cabernet sauvignon wine from Changli County, Natural Science, 1(3), pp. 176-182, DOI:10.4236/health.2009.13028

33. Fedrizzi B. et al. (2011), Changes in Wine Aroma Composition According to Botrytized Berry Percentage: A Preliminary Study on Amarone Wine, Food Technol. Biotechnol, 49(4), pp. 529-535.

34. Delgadillo I. et al. (2004), Volatile composition of Baga red wine: Assessment of the identification of the would- be impact odourants, Analytica Chimica Acta, 513, pp. 257-262. DOI: 10.1016/j.aca.2003.10.009

35. Agraria D. et al. (2012), Free and Enzymatically Hydrolysed Volatile Compounds of Sweet Wines from Malvasia and Muscat Grapes (Vitis vinifera) grown in Sardinia, $S$. Afr. J. Enol. Vitic., 33(1), pp. 115-121.

36. Park H. et al. (2013), Characterization of Volatile Components in Makgeolli, a Traditional Korean Rice Wine, with or without Pasteurization, During Storage. Molecules, 18, pp. 5317-5325. 